\title{
Use of infliximab in treatment of acute pancreatitis
}

\author{
Ozcevik Tekin $\mathrm{S}^{1}$, Teksoz $\mathrm{S}^{2}$, Terzioglu $\mathrm{D}^{3}$, Arikan $\mathrm{AE}^{2}$, Ozcevik $\mathrm{H}^{2}$, Uslu $\mathrm{E}^{3}$ \\ Istanbul University, Cerrahpasa Medical Faculty, Department of General Surgery, Istanbul, Turkey. \\ serkanteksoz@gmail.com
}

\begin{abstract}
Objective:The aim of this study was to investigating the effects of infliximab in severe necrotizing pancreatitis.

Methods: Forty male Wistar rats were randomly divided into five groups evenly. Necrotizing pancreatitis was induced in group I and II by retrograde injection of $3 \%$ taurocholate into common pancreaticobiliary duct. In group III and IV saline was introduced instead of taurocholate to mimic pressure effect. Infliximab (8mg/kg) was infused through tail vein in group I and III and saline was infused in group II and IV just before laparotomy. Group V underwent sham laparotomy. Serum amylase activity, serum and tissue sialic acid, carbonyl content, malondialdehyde, total antioxidant activity (TAA) and pancreatic histopathology were assessed.

Results: In group I serum sialic acid, malondialdehyde, carbonyl content and amylase activity were significantly lower than in group II $(p<0.01)$. There were no significant differences for serum TAA between group I and II $(p>0.05)$. Tissue sialic acid and malondialdehyde in group I were significantly lower than in group II $(p<0.01)$. But tissue TAA in group I was significantly higher than in group II $(p<0.01)$. Carbonyl content of group I was not significantly different from group II ( $p>0.05)$. Histopathologically, pancreatic sections of group II demonstrated extensive acinar and fat necrosis, hemorrhage, and inflammation. In group I Infliximab improved histopathological changes $(p<0.01)$, but not edema $(p>0.05)$.

Conclusion: Administration of infliximab resulted in a significant improvement in biochemical and histopathological alterations in acute necrotizing pancreatitis (Tab. 3, Ref. 43). Text in PDF www.elis.sk.

Keywords: acute necrotizing pancreatitis, infliximab, TNF-alpha; taurocholate, malondialdehyde, amylase, antioxidants, sialic acid.
\end{abstract}

\section{Introduction}

Acute pancreatitis is a multifactorial disease that leads to systemic inflammatory response (1-4). The main pathological mechanism of damage is early activation of digestive enzymes in pancreatic acinus; but also apoptosis of pancreatic acinar cells, increased oxidative stress, micro-vascular damage and release of cytokines allow progression of the damage and development of extra pancreatic complications (1-6). Severe acute pancreatitis usually develops as a result of glandular necrosis (7). Nuclear factor $-\mathrm{\kappa B}(\mathrm{NF}-\mathrm{\kappa} \mathrm{B})$, a transcription factor associated with early gene activation, plays a critical role in the development of necrosis. Even though the real mechanism of NF-KB activation is unknown, once stimulated it leads to the production of various inflammatory cytokines including tumor necrosis factor alpha (TNF- $\alpha)(8)$. TNF- $\alpha$ is a cytokine primarily derived from macrophages which plays a major role in formation of many pathophysiological responses of the organism to injury or disease. Systemic symptoms in septic

'Istanbul Mehmet Akif Ersoy Teaching and Research Hospital, Department of General Surgery, Istanbul, Turkey, ${ }^{2}$ Istanbul University, Cerrahpasa Medical Faculty, Department of General Surgery, Istanbul, Turkey, and ${ }^{3}$ Istanbul University, Cerrahpasa Medical Faculty, Department of Medical Biochemistry, Istanbul, Turkey

Address for correspondence: S. Teksoz, MD, Cerrahpasa Tip Fakultesi, Genel Cerrahi AD 34098 Fatih, Istanbul, Turkey.

Phone: +90.505 .6689077 , Fax: +90.212 .4143370$ shock which is associated with increased TNF- $\alpha$ level, shows a close resemblance in patients with severe acute pancreatitis. All of this kind of complications may be due to cellular response such as excessive neutrophil activation, increased capillary permeability and direct cellular toxicity. As shown in septic shock syndrome these cellular responses are associated with TNF- $\alpha$ production (9). In terms of central importance of IL-1 and TNF as the mediators of inflammatory response, researchers accept that blocking the production and the effects of these cytokines is a strategy that makes sense in the treatment of various conditions associated with excessive and uncontrolled inflammation. One of the agents designed to neutralize the effects of the secreted TNF- $\alpha$ is infliximab; a monoclonal anti-TNF- $\alpha$ antibody (10). The purpose of this study is to investigate the therapeutic effect of monoclonal TNF- $\alpha$ antibody Infliximab by determining its effect on oxidative stress and histopathological changes caused by pancreatitis in severe necrotizing pancreatitis model induced in rats.

\section{Material and methods}

The research was performed with the approval of the Experimental Animal Ethics Committee Istanbul University, Cerrahpasa Medical Faculty. In the randomized controlled experimental study 40 male Wistar albino rats obtained from Istanbul University, Cerrahpasa Medical Faculty Research Laboratories each weighing approximately 250 grams $(240-310 \mathrm{~g})$ were used. The subjects 


\section{7-172}

were fed with standard diet and water ad libitum for two weeks of adaptation before the experiment with the guidance of Guide to the Care and Use of Laboratory Animals (11). Rats were held in a room with temperature of $23 \pm 2{ }^{\circ} \mathrm{C}, 60 \pm 10 \%$ humidity and under 12-hours day-night cycles.

\section{Infliximab Application}

Infliximab was dissolved in sterile distilled water and diluted with saline solution. Infliximab was infused into the tail vein of rats at a dose of $8 \mathrm{mg} / \mathrm{kg}$.

Rats were anesthetized by $10 \mathrm{mg} / \mathrm{kg}$ intramuscular injection of xylazine and $50 \mathrm{mg} / \mathrm{kg}$ intraperitoneal injection of ketamine. Severe necrotizing pancreatitis was induced by intraductal infusion of 3\% sodium taurocholate (taurocholate). Laparotomy was performed with bilateral subcostal incision, under sterile conditions. Choledoche was put forth by hanging the distal part with $2 / 0$ silk. Sterile $3 \%$ sodium taurocholate was withdrawn into the insulin injector in a dosage of $0.1 \mathrm{ml} / 100 \mathrm{~g}$ and was infused slowly to the pancreaticobiliary duct. At the end of the taurocholate infusion needle and the silk hang was released.

\section{The experimental groups were created as follows:}

Group I ( $\mathrm{n}=8)$ : Infliximab was infused through tail vein at dose of $8 \mathrm{mg} / \mathrm{kg}$ for 20 minutes. Acute pancreatitis was induced by intraductal infusion of 3\% taurocholate.

Group II $(n=8)$ : Saline was infused through tail vein for 20 minutes. Then acute pancreatitis was induced by intraductal infusion of $3 \%$ taurocholate.

Group III ( $\mathrm{n}=8)$ : Infliximab was infused through tail vein at a dose of $8 \mathrm{mg} / \mathrm{kg}$ for 20 minutes. Then $0.1 \mathrm{ml} / 100 \mathrm{~g}$ saline was infused by intraductal route.

Group IV ( $\mathrm{n}=8)$ : In the control group $0.1 \mathrm{ml} / 100 \mathrm{~g}$ saline was infused by intraductal route and $2 \mathrm{ml}$ saline was infused into the tail vein.

Group V ( $\mathrm{n}=8)$ : The rats underwent sham laparotomy.

All rats were sacrificed 8 hours after intraductal infusion of taurocholate or saline.

Fluid replacement of rats was maintained with $1 \mathrm{ml} / 100 \mathrm{~g}$ saline infusion in postoperative period. Rats were sacrificed after 8 hours from taurocholate and saline infusion. Blood samples were taken by intra-cardiac puncture after thoracotomy. Pancreas was extracted quickly by re-laparotomy.

Half of the pancreas tissue was put in $10 \%$ formalin, and was sent to the pathology laboratory for histopathological examination. The other half was placed in the freezer at $-70^{\circ} \mathrm{C}$ temperature.

\section{Biochemical analysis}

Amylase activity was studied promptly on the taken blood samples. Blood samples were centrifuged for 5 minutes at 2500rpm. Serum amylase activity was measured and the results were stated as $\mathrm{U} / \mathrm{L}$ unit. Remaining serum samples were stored in freezer at $-70^{\circ} \mathrm{C}$ to analyze antioxidant activity.

Malondialdehyde (MDA), indicator of lipid peroxidation, was determined with modified thiobarbituric acid method defined by Buege et al (12) and expressed in $\mu \mathrm{M}$.
Serum sialic acid level was measured by using Warren thiobarbituric acid test and was expressed in $\mathrm{mg} / \mathrm{dl}$ (13).

Protein carbonylation assay (carbonyl content, CC) was assessed with Levine's method and stated as nmol/mg (14).

Determination of protein content (PC) was calculated by Lowry method (15).

Determination of antioxidant activity (total antioxidant activity, TAA) was calculated as described below. Standard solution of Fe-EDTA reacts with hydrogen peroxide via Fenton type reaction and hydroxyl radical $\left({ }^{\circ} \mathrm{OH}\right)$ occurs. This reactive oxygen particles shreds benzoate and thiobarbituric acid reactive substances (TBARS) occur. Antioxidants inside the sample suppress TBARS formation. Spectrophotometric measurement of inhibition of color formation at $532 \mathrm{~nm}$ is stated as antioxidant activity (16).

The same methods were used in the tissue study. But tissues were homogenized in phosphate buffer at $\mathrm{pH}$ of 7.4 before the processes. After separating the parts that didn't break down after centrifugation, homogenate was studied by the method applied in the serum. Results obtained from the tissue were calculated by proportioning over protein in milligram. Lowry protein method was used to determine protein content (15).

\section{Histopathological analysis}

Pancreas tissue sample set aside for pathologic examination was sunk into $10 \%$ buffered formalin immediately. Then pancreatic tissue samples were prepared as paraffin blocks, cut and stained with hematoxylin-eosin. They were analyzed using light microscope. Severity of necrotizing pancreatitis was evaluated according to the scoring system defined by Spormann et al (17) (Tab. 1).

\section{Statistical analysis}

Evaluation of the findings was performed with SPSS 20 for Windows software. While analyzing data from the study besides the definitive statistical methods (mean value, standard deviation), to analyze the parameters showing normal range as a result of comparison of quantitative data by Kolmogoroff-Smirnoff test, Oneway ANOVA test and post-hoc Tukey-HSD test; for pathologic

Tab. 1.Scoring system for severity of necrotizing pancreatitis described by Spormann et al(Spormann et al, 1989).

\begin{tabular}{lcc}
\hline Histopathological pattern & Evaluation & Score \\
\hline Edema & Mild & 1 \\
& Moderate & 2 \\
& Severe & 3 \\
\hline Inflammatory infiltration & Mild & 1 \\
& Moderate & 2 \\
& Severe & 3 \\
\hline Fat necrosis & $<2 /$ section & 3 \\
& $3-5 /$ section & 5 \\
\hline Parenchymal necrosis & $>5 /$ section & 7 \\
& Focal $(<5 \%)$ & 3 \\
& Sublobular $(<20 \%)$ & 5 \\
\hline Hemorrhage & Lobular $(>20 \%)$ & 7 \\
& Mild & 3 \\
& Moderate & 5 \\
\hline
\end{tabular}


analysis Kruskal-Wallis test and Mann-Whitney-U test were used. Results were assessed in $95 \%$ confidence interval, and significance level accepted as $\mathrm{p}<0.05$.

\section{Results}

Distribution of groups in terms of serum sialic acid indicates statistically significant difference $(\mathrm{p}<0.01)$. In Tukey's post-hoc test performed to check which group has the significance, the mean sialic acid level of Group II was significantly higher than the other groups (respectively $\mathrm{p}=0.001, \mathrm{p}=0.001, \mathrm{p}=0.006, \mathrm{p}=0.001$ ). There wasn't a significant difference between the mean sialic acid levels of other groups ( $p>0.05)$.

Distribution of groups in terms of serum TAA concentration indicates statistically significant difference $(p<0.05)$. In Tukey's post-hoc test mean TAA level of Group II was higher than Group III $(p=0.048)$. There wasn't a significant difference between TAA levels of the other groups ( $p>0.05$ ).

Distribution of groups in terms of serum MDA concentration indicated statistically significant difference $(p<0.01)$. In Tukey's post-hoc test the mean MDA level of Group II was higher than the other groups in advanced level $(\mathrm{p}=0.001, \mathrm{p}=0.001, \mathrm{p}=0.038$, $\mathrm{p}=0.001$, respectively). There wasn't a significant difference between MDA levels of other groups ( $\mathrm{p}>0.05)$.

Distribution of groups in terms of serum CC levels indicated statistically significant difference $(\mathrm{p}<0.01)$. In Tukey's post-hoc test CC level of Group I was significantly lower than Group II and Group IV (respectively p=0.001, p=0.004); the meanCC level of Group II was significantly higher than Group III and Group V (respectively $\mathrm{p}=0.001, \mathrm{p}=0.001$ ). CC level of Group III was significantly lower than Group IV ( $p=0.001)$; CC level of Group IV was significantly higher than Group V ( $\mathrm{p}=0.001)$; there wasn't a significant difference between other CC levels $(\mathrm{p}>0.05)$.
Distribution of groups in terms of serum amylase levels indicated statistically significant difference $(\mathrm{p}<0.01)$. In Tukey's post-hoc test amylase level of Group I was significantly lower than in Group II and Group IV (respectively $p=0.001, p=0.016$ ); the mean amylase level of Group II was higher than in Group III, Group IV and Group V (respectively $\mathrm{p}=0.001, \mathrm{p}=0001, \mathrm{p}=0.001$ ). Amylase level of Group III was significantly lower than Group IV $(\mathrm{p}=0.019)$; amylase level of Group IV was significantly higher than Group V ( $p=0.001)$. There wasn't a significant difference between other amylase levels $(\mathrm{p}>0.05)$.

Distribution of groups in terms of tissue sialic acid concentration indicated statistically significant difference $(p<0.01)$. In Tukey's post-hoc test the mean tissue sialic acid level in Group II was significantly higher than in Group I, Group III, and Group $\mathrm{V}$ (respectively $\mathrm{p}=0.001, \mathrm{p}=0.001, \mathrm{p}=0.013$ ). Sialic acid levels of Group III were significantly lower than in Group IV $(\mathrm{p}=0.014)$. There wasn't a significant difference between the mean sialic acid levels of other groups ( $\mathrm{p}>0.05)$.

Distribution of groups in terms of tissue TAA concentration indicated statistically significant difference $(p<0.01)$. In Tukey's post-hoc test mean TAA level of Group I was significantly higher than of Group II, Group IV and Group V ( $p=0.004, p=0.001$, $\mathrm{p}=0.036$ ). TAA level of Group III was significantly higher than of Group IV ( $\mathrm{p}=0.033$ ). There wasn't a statistically significant difference between TAA levels of other groups ( $p>0.05)$.

Distribution of groups in terms of tissue MDA concentration indicated statistically significant difference $(p<0.01)$. In Tukey's post-hoc test the mean MDA level of Group I was significantly lower than in Group II; Group IV and Group V ( $p=0.002$, $p=0.020, p=0.001$, respectively). MDA level of Group II was significantly higher than of Group III $(\mathrm{p}=0.003)$. MDA level of Group III was significantly lower than of Group IV and Group $\mathrm{V}(\mathrm{p}=0.024, \mathrm{p}=0.001)$. MDA level of Group IV was significantly

Tab. 2.Serum and tissue levels of analyzed values.

\begin{tabular}{|c|c|c|c|c|c|c|c|}
\hline & Group 1 & Group 2 & Group 3 & Group 4 & Group 5 & $\mathrm{~F}$ & $\mathrm{p}$ \\
\hline Sialic Acid (Serum) (mg/dl) & $64.88 \pm 5.64$ & $79.10 \pm 4.29$ & $66.15 \pm 4.87$ & $69.61 \pm 4.92$ & $68.33 \pm 5.51$ & 9.775 & 0.001 \\
\hline Total Antioxidant Activity (Serum) & $0.834 \pm 0.261$ & $0.993 \pm 0.116$ & $0.725 \pm 0.158$ & $0.741 \pm 0.198$ & $0.880 \pm 0.108$ & 3.023 & 0.03 \\
\hline Malondialdehyde (Serum) $(\mu \mathrm{M})$ & $9.57 \pm 1.37$ & $15.76 \pm 4.08$ & $9.49 \pm 2.24$ & $11.93 \pm 2.76$ & $10.43 \pm 1.19$ & 8.316 & 0.001 \\
\hline Carbonyl content (Serum) (nmol/mg) & $1.451 \pm 0.219$ & $2.495 \pm 0.276$ & $1.393 \pm 0.180$ & $2.127 \pm 0.604$ & $1.258 \pm 0.281$ & 19.165 & 0.001 \\
\hline Amylase (Serum) & $1987.13 \pm 478.57$ & $4200 \pm 960.38$ & $1799.13 \pm 705.41$ & $2820.75 \pm 517.30$ & $943.25 \pm 176.24$ & 31.106 & 0.001 \\
\hline Sialic Acid (Tissue) (mg/dl) & $18.42 \pm 4.17$ & $32.68 \pm 9.44$ & $14.65 \pm 4.80$ & $24.88 \pm 6.45$ & $22.42 \pm 3.00$ & 10.393 & 0.001 \\
\hline Total Antioxidant Activity (Tissue) & $0.253 \pm 0.071$ & $0.157 \pm 0.042$ & $0.208 \pm 0.029$ & $0.133 \pm 0.054$ & $0.179 \pm 0.036$ & 7.174 & 0.001 \\
\hline Malondialdehyde (Tissue) $(\mu \mathrm{M})$ & $0.762 \pm 0.166$ & $1.367 \pm 0.289$ & $0.774 \pm 0.223$ & $1.247 \pm 0.433$ & $1.728 \pm 0.304$ & 15.369 & 0.001 \\
\hline Carbonyl content (Tissue) (nmol/mg) & $48.921 \pm 7.910$ & $41.485 \pm 0.897$ & $33.866 \pm 3.629$ & $38.292 \pm 3.520$ & $35.215 \pm 7.022$ & 10.433 & 0.001 \\
\hline
\end{tabular}

All values were expressed as mean \pm standard deviation. p values lower than 0.05 were accepted as statistically significant. Statistical analyzes were performed with OneWay ANOVA test.

Tab. 3.Histopathological assessment of pancreatic tissue sections for each group.

\begin{tabular}{lccccccc}
\hline & Group 1 & Group 2 & Group 3 & Group 4 & Group 5 & KW & p \\
\hline Edema & $2.00 \pm 0.53$ & $2.50 \pm 0.75$ & $2.00 \pm 0.53$ & $3.00 \pm 0.0$ & $1.50 \pm 0.53$ & 21.204 & 0.001 \\
\hline Inflammation & $0.87 \pm 0.35$ & $1.62 \pm 0.51$ & $1.25 \pm 0.46$ & $1.87 \pm 0.64$ & $0.75 \pm 0.88$ & 14.076 & 0.001 \\
\hline Fat necrosis & $2.75 \pm 1.90$ & $5.75 \pm 1.03$ & $1.50 \pm 1.60$ & $2.37 \pm .13$ & $0.0 \pm 0.0$ & 24.459 & 0.001 \\
\hline Parenchyma necrosis & $0.37 \pm 1.06$ & $4.87 \pm 2.16$ & $0.37 \pm 1.06$ & $1.00 \pm 1.92$ & $0.0 \pm 0.0$ & 22.467 & 0.001 \\
\hline Hemorrhage & $1.75 \pm 1.48$ & $4.75 \pm 1.66$ & $1.87 \pm 1.55$ & $1.00 \pm 1.92$ & $0.62 \pm 1.87$ & 17.904 & 0.001 \\
\hline
\end{tabular}

All values were expressed as mean \pm standard deviation. p values lower than 0.05 were accepted as statistically significant. Statistical analyzes were performed with Kruskal-Wallis $(\mathrm{KW})$ test. 


\section{7-172}

lower than of Group V ( $p=0.021)$. There wasn't a significant difference between MDA levels of other groups ( $p>0.05$ ).

Distribution of groups in terms of tissue CC levels indicated statistically significant difference $(p<0.01)$. In Tukey's post-hoc test CC level in Group I was significantly higher than in Group III, Group IV and Group V ( $\mathrm{p}=0.001, \mathrm{p}=0.002, \mathrm{p}=0.001$, respectively); the meanCC level of Group II was significantly higher than of Group III ( $p=0.047)$. There were no significant differences between other CC levels ( $p>0.05$ ).

Statistically significant difference $(p<0.01)$ was observed between groups in terms of edema. In Mann-Whitney U test edema analysis of Group I was significantly lower than of Group IV $(p=0.001)$, Group II was significantly higher than Group V $(p=0.014)$. Edema analysis of Group III was significantly lower than of Group IV ( $p=0.001)$, Group IV was significantly higher than Group V ( $\mathrm{p}=0.001)$. There wasn't a statistically significant difference between other groups for edema analysis $(p>0.05)$.

Statistically significant difference $(p<0.01)$ was observed between groups in terms of inflammation. In Mann-Whitney U test inflammation analysis of Group I was significantly lower than of Group II and Group IV ( $p=0.008, p=0.003$ ), Group II was significantly higher than Group V ( $\mathrm{p}=0.043)$. Inflammation analysis of Group III was significantly lower than of Group IV ( $p=0.045)$, Group IV was significantly higher than Group V $(p=0.019)$. There wasn't a statistically significant difference between other groups for inflammation analysis ( $\mathrm{p}>0.05$ ).

Statistically significant difference $(p<0.01)$ was observed between groups in terms of fat necrosis. In Mann-Whitney U test fat necrosis analysis of Group I was significantly lower than of Group II and significantly higher than of Group V ( $p=0.003$, $\mathrm{p}=0.003$, respectively), Group II was significantly higher than Group III, Group IV, and Group V ( $\mathrm{p}=0.001, \mathrm{p}=0.003, \mathrm{p}=0.001$, respectively). Fat necrosis analysis of Group III was significantly higher than of Group V ( $\mathrm{p}=0.025)$, fat necrosis analysis of Group IV was significantly higher than of Group V $(p=0.010)$. There wasn't a statistically significant difference between other groups for fat necrosis analysis $(\mathrm{p}>0.05)$.

Statistically significant difference $(p<0.01)$ was observed between groups in terms of parenchymal necrosis. In Mann-Whitney U test parenchymal necrosis analysis of Group I was significantly lower than of Group II ( $\mathrm{p}=0.002$ ), parenchymal necrosis analysis of Group II was significantly higher than of Group III, Group IV, and Group V ( $\mathrm{p}=0.002, \mathrm{p}=0.006, \mathrm{p}=0.001$, respectively). There wasn't a statistically significant difference between other groups for parenchymal necrosis analysis $(\mathrm{p}>0.05)$.

Statistically significant difference $(p<0.01)$ was observed between groups in terms of hemorrhage. In Mann-Whitney U test, hemorrhage analysis of Group I was significantly lower than of Group II ( $p=0.004)$, Group II was significantly higher than Group III, Group IV, and Group V ( $\mathrm{p}=0.006, \mathrm{p}=0.004, \mathrm{p}=0.001$, respectively). There wasn't a statistically significant difference between other groups for hemorrhage analysis $(\mathrm{p}>0.05)$.

Detailed results of serum and tissue mean levels and histopathological results are shown in Tabs 2 and 3.

\section{Discussion}

Since Heinkel (18) defined taurocholate induced acute necrotizing pancreatitis model, this model has been widely used (19-22). Increasing the concentration of taurocholate increases the severity of pancreatitis. While the infusion of $2 \%$ taurocholate results in a small necrosis and low mortality, infusion of 5\% taurocholate results in fatal pancreatitis within hours. In pancreatitis model of Schwarz et al (23), to get a survey of 36 hours, 3\% taurocholate injection was applied and severe necrotizing acute pancreatitisoccurred within 8 hours. In this study, model of pancreatitis generated by Schwarz was preferred and 3\% taurocholate solution was infused into the common bile duct. Distinctive fat and parenchymal necrosis was detected in pancreas tissue samples which were taken eight hours after induction of pancreatitis with sacrification of rats.

TNF- $\alpha$ is a cytokine which was primarily derived from macrophages and plays a major role in the formation of many pathophysiological responses of the organism to injury or disease. Systemic symptoms in septic shock which are associated with increased TNF- $\alpha$ level, show a close resemblance to patients with severe acute pancreatitis (9).

In experimental acute pancreatitis, identification of TNF gene increases in the first hour. Sudden increase of TNF- $\alpha$ activity in the serum of animals with pancreatitis occurs within 1-3 hours after the induction of the disease (24). Thus it would be reasonable to prevent the activity of TNF- $\alpha$ by infliximab as early as possible. In the study of Oruc et al. (25), infliximab was given at the beginning of pancreatitis and observed as significantly effective. Due to rapid destruction of TNF- $\alpha$, it has a very short half-life up to 14-18 minutes. Therefore, TNF- $\alpha$ absence or very low levels in the serum may not correlate with the actual pathology (26). In the study of Hughes et al (24) anti-TNF- $\alpha$ antibodies were applied 15 minutes before the induction of pancreatitis, on the other hand in the study of Grewal et al (9) 30 minutes before the induction of pancreatitis. Related to this situation the maximum beneficial effect of anti-TNF- $\alpha$ treatment is obtained when applied immediately after the pancreatitis begins. Norman et al (27) insist on that; delaying the TNF- $\alpha$ antagonist until pancreatitis occurs and cytokine level increases (but not to maximum) is more effective than prophylactic antagonism. In this study, application of the infliximab infusion just before the induction of pancreatitis gave significant biochemical and histopathological results.

The effect of TNF- $\alpha$ neutralization on improvement of systemic complications of acute pancreatitis can be best explained by analyzing the known effects of TNF- $\alpha$. Itis considered that TNF- $\alpha$ increases the vascular permeability by a direct effect on vascular endothelium and also by indirect mechanisms involving leukocytes (9). In this way it increases the collection and activation of leukocytes in inflammation area (28). It is known that activated leukocytes secrete various mediators under the effect of TNF- $\alpha$ which is known to increase the vascular permeability. These mediators include platelet activating factor (PAF), nitric oxide, phospholipase A2 and free oxygen radicals (28-33).

It has been reported that free oxygen radicals of these mediators play an important role in the pathogenesis of acute pancreatitis 
$(34,35)$. It is known that reactive oxygen radicals are produced in various pathological conditions, cause cellular damage by lipid peroxidation and protein oxidation. The oxidative effects of free radicals on lipid and proteins are controlled by an antioxidant spectrum. Differentiating levels of lipid peroxides, protein carbonyl content, antioxidant vitamins and activities of antioxidant enzymes were studied often in patients to observe oxidative stress. Moreover, it was reported that besides protein, lipid and DNA, unreduced terminal sialic acid fragments may be the target molecule of reactive oxygen molecules. Reactive oxygen molecules specifically break down and release the sialic acid fragments. Sialic acid is located in terminal part of carbohydrate chains of glycolipids and glycoproteins. Its functions in biological systems are adaptation, protease resistance, load, cellular recognition, protein to be targeted and developmental regulation (36).

Carbonylation is a marker of oxidative damage of proteins. It is stated that measuring total antioxidant activity level provides an integrated indicator, corresponding to a result based on a simple sum of antioxidants (37). In this study, oxidative stress was evaluated by using MDA - a lipid peroxidation product -, carbonyl content, sialic acid, and total antioxidant activity parameters. Serum sialic acid and MDA level were found significantly higher than in the other groups in pancreatitis induced group (Group II) ( $p<0.01)$. Carbonyl content levels were found significantly higher than infliximab applied group (Group I) in pancreatitis group (Group II) $(\mathrm{p}<0.01)$.

Itis believed that increased oxyradical level and decreased antioxidant level in systemic inflammatory response syndrome (SIRS) lead to multiple organ failure (38). But increased serum total antioxidant capacity was observed in critical surgical patients in septic shock (39). Also increased endogenous peroxyradical catch capacity was found in plasma samples of non-living SIRS patients (40). So, TAA level in serious sepsis conditions is still discutable(38). In this study, there was a significant difference in terms of serum TAA levels between Group II and Group III $(p<0.05)$ but there wasn't a significant difference among other groups $(p>0.05)$. But in terms of tissue TAA levels, in infliximab applied group it was detected significantly higher than pancreatitis group.

Hyperamylasemia is an indicator of pancreas acinar cell damage. Even though the relation of various TNF- $\alpha$ induced mediators with acinar cell damage has shown, the etiology of acinar cell damage has not been well defined yet. These mediators include activated proteolytic enzymes, phospholipase A2 and free oxygen radicals and they can be measured in serum, urine and ascites fluids of all humans and animals with acute pancreatitis. Neutralization of TNF- $\alpha$ decreases the levels of these mediators and therefore improves acinar cell damage and hyperamylasemia(9). In this study, serum amylase level with TNF- $\alpha$ neutralization was found significantly higher than control groups in pancreatitis induced group $(p<0.01)$ and in infliximab applied group was significantly lower than pancreatitis induced group $(\mathrm{p}<0.01)$. In the past ten years a lot of studies showing the beneficial effect of blocking TNF- $\alpha$ in acute pancreatitis were published. Hughes et al (24) showed that anti TNF- $\alpha$ antibody improved the complications related to acute pancreatitis in rats. Grewal et al (9) showed significant improvement in biochemical findings using polyclonal blocking of TNF- $\alpha$.
But there wasn't any significant difference in histologic analysis of pancreatitis with polyclonal anti-TNF- $\alpha$ antibody use. Similarly Norman et al (40) showed that mortality and severity decreased by using soluble TNF- $\alpha$ receptor antagonist in experimentally induced pancreatitis. Guice et al (41) showed increase of pancreatic edema after the treatment with TNF- $\alpha$ antagonist. Oruc et al (25) showed that Infliximab plays an anti-inflammatory role in acute edematous pancreatitis especially by suppressing neutrophil activity, but they didn't detect differencesin pancreatic edema. On the other hand in the severe necrotizing pancreatitis model they induced they showed that Infliximab significantly improves parenchymal and fat necrosis but doesn't change neutrophil activity and pancreatic edema. In this study, infliximab induction caused significantimprovements in fat necrosis, parenchymal necrosis and hemorrhage findings were observed in necrotizing pancreatitis model $(\mathrm{p}<0.01)$. Unlikely, there was a significant improvement in neutrophil infiltration $(p<0.01)$. But edema didn't show a significant difference between group I and group II ( $\mathrm{p}>0.05)$.

There is no published data showing the therapeutic effect of infliximab in acute pancreatitis. But infliximab application was reported by Trientafillidis et al (42) in the treatment of acute pancreatitis as a complication of resistant Crohn's disease. According to knowledge of TNF- $\alpha$ based pathophysiology in Crohn's disease and acute pancreatitis they decided to treat this patient with Infliximab. They got a perfect result after two session of treatment with two infliximab infusion at each time. On the contrary, recurrent chronic pancreatitis episodes were detectedin a case using infliximab for Crohn's disease as reported by Fefferman et al (43). Thus, more studies are needed to investigate the effects of TNF- $\alpha$ on acute pancreatitis and the therapeutic effect of infliximab.

\section{Conclusion}

Results from applying infliximab, an anti-TNF- $\alpha$ monoclonal antibody, in the acute necrotizing pancreatitis model which was induced with taurocholate are promising. TNF- $\alpha$ plays an important role in pathogenesis of acute pancreatitis. Significant improvement was obtained in biochemical and histopathological findings of acute pancreatitis by infliximab use. This study may lead the way to clinical researches of infliximab for acute pancreatitis.

\section{References}

1. Yamanel L, Mas MR, Comert B et al. The effect of activated protein C on experimental acute necrotizing pancreatitis. Crit Care 2005; 9 (3): R184-190.

2. Neoptolemos JP, Raraty M, Finch M, Sutton R. Acute pancreatitis: the substantial human and financial costs. Gut 1998; 42 (6): 886-891.

3. Norman J. The role of cytokines in the pathogenesis of acute pancreatitis. Am J Surg 1998; 175 (1): 76-83.

4. Gomez-Cambronero LG, Sabater L, Pereda J et al. Role of cytokines and oxidative stress in the pathophysiology of acute pancreatitis: therapeutical implications. Curr Drug Targets Inflamm Allergy 2002; 1 (4): 393-403.

5. Forsmark CE, Toskes PP. Acute pancreatitis. Medical management. Crit Care Clin 1995; 11 (2): 295-309. 
167-172

6. Whitcomb DC. Acute pancreatitis: molecular biology update. J Gastrointest Surg 2003; 7 (8): 940-942.

7. Baron TH, Morgan DE. Acute necrotizing pancreatitis. N Engl J Med 1999; 340 (18): 1412-1417.

8. Pezzilli R, Ceciliato R, Barakat B, Corinaldesi R. Immune-manipulation of the inflammatory response in acute pancreatitis. What can be expected? JOP 2004; 5 (3): 115-121.

9. Grewal HP, Mohey el Din A, Gaber L, Kotb M, Gaber AO. Amelioration of the physiologic and biochemical changes of acute pancreatitis using an anti-TNF-alpha polyclonal antibody. Am J Surg 1994; 167 (1): 214-218; discussion 218-219.

10. Fink MP. The role of cytokines as mediators of the inflamatory response. In: Sabiston DCTCM, eds. Sabiston textbook of surgery : the biological basis of modern surgical practice. Philadelphia, Saunders/Elsevier; 2008, p, 28-43.

11. National Research Council CotCaUoLA, Institute for Laboratory Animal Research. Guide for the care and use of laboratory animals. Washington, D.C., National Academies Press; 2011.

12. Buege JA, Aust SD. Microsomal lipid peroxidation. Methods Enzymol 1978; 52: 302-310.

13. Warren L. The thiobarbituric acid assay of sialic acids. J Biol Chem 1959; 234 (8): 1971-1975.

14. Levine RL, Garland D, Oliver CN et al. Determination of carbonyl content in oxidatively modified proteins. Methods Enzymol 1990; 186: 464-478.

15. Lowry OH, Rosebrough NJ, Farr AL, Randall RJ. Protein measurement with the Folin phenol reagent. J Biol Chem 1951; 193 (1): 265-275.

16. Koracevic D, Koracevic G, Djordjevic V, Andrejevic S, Cosic V. Method for the measurement of antioxidant activity in human fluids. J Clin Pathol 2001; 54 (5): 356-361.

17. Spormann H, Sokolowski A, Letko G. Effect of temporary ischemia upon development and histological patterns of acute pancreatitis in the rat. Pathol Res Pract 1989; 184 (5): 507-513.

18. Heinkel K. [The rat as experimental animal in experimental diagnosis of pancreas. II. Production of acute hemorrhagic pancreatitis by injection of bile acid into ductus pancreaticus]. Klin Wochenschr 1953; 31 (33-34): 815.

19. Adler G, Kern H, Scheele G. Experimental models and concepts in acute pancreatitis. In: Go VLW, eds. The Pancreas : biology, pathobiology, and disease. New York: Raven Press, 1993, p.407-421.

20. Bilchik AJ, Leach SD, Zucker KA, Modlin IM. Experimental models of acute pancreatitis. J Surg Res 1990; 48 (6): 639-647.

21. Aho HJ, Koskensalo SM, Nevalainen TJ. Experimental pancreatitis in the rat. Sodium taurocholate-induced acute haemorrhagic pancreatitis. Scand J Gastroenterol 1980; 15 (4): 411-416.

22. Aho HJ, Nevalainen TJ. Experimental pancreatitis in the rat. Ultrastructure of sodium taurocholate-induced pancreatic lesions. Scand J Gastroenterol 1980; 15 (4): 417-424.

23. Schwarz M, Thomsen J, Meyer H, Buchler MW, Beger HG. Frequency and time course of pancreatic and extrapancreatic bacterial infection in experimental acute pancreatitis in rats. Surgery 2000; 127 (4): 427-432.

24. Hughes CB, Grewal HP, Gaber LW et al. Anti-TNFalpha therapy improves survival and ameliorates the pathophysiologic sequelae in acute pancreatitis in the rat. Am J Surg 1996; 171 (2): 274-280.

25. Oruc N, Ozutemiz AO, Yukselen V et al. Infliximab: a new therapeutic agent in acute pancreatitis? Pancreas 2004; 28 (1): e1-8.

26. Makhija R, Kingsnorth AN. Cytokine storm in acute pancreatitis. J Hepatobiliary Pancreat Surg 2002; 9 (4): 401-410.
27. Norman JG, Fink GW, Messina J, Carter G, Franz MG. Timing of tumor necrosis factor antagonism is critical in determining outcome in murine lethal acute pancreatitis. Surgery 1996; 120 (3): 515-521.

28. Ming WJ, Bersani L, Mantovani A. Tumor necrosis factor is chemotactic for monocytes and polymorphonuclear leukocytes. J Immunol 1987; 138 (5): 1469-1474.

29. Rabinovici R, Yue TL, Farhat $M$ et al. Platelet activating factor (PAF) and tumor necrosis factor-alpha (TNF alpha) interactions in endotoxemic shock: studies with BN 50739, a novel PAF antagonist. J Pharmacol Exp Ther 1990; 255 (1): 256-263.

30. Estrada C, Gomez C, Martin C, Moncada S, Gonzalez C. Nitric oxide mediates tumor necrosis factor-alpha cytotoxicity in endothelial cells. Biochem Biophys Res Commun 1992; 186 (1): 475-482.

31. van den Bosch H, Schalkwijk C, Pfeilschifter J, Marki F. The induction of cellular group II phospholipase A2 by cytokines and its prevention by dexamethasone. Adv Exp Med Biol 1992; 318: 1-10.

32. Bauldry SA, McCall CE, Cousart SL, Bass DA. Tumor necrosis factor-alpha priming of phospholipase A2 activation in human neutrophils. An alternative mechanism of priming. J Immunol 1991; 146 (4): 1277-1285.

33. Suffys P, Beyaert R, De Valck D, Vanhaesebroeck B, Van Roy F, Fiers W. Tumour-necrosis-factor-mediated cytotoxicity is correlated with phospholipase-A2 activity, but not with arachidonic acid release per se. Eur J Biochem 1991; 195 (2): 465-475.

34. Schoenberg MH, Birk D, Beger HG. Oxidative stress in acute and chronic pancreatitis. Am J Clin Nutr 1995; 62 (6 Suppl): 1306S-1314S.

35. Sweiry JH, Mann GE. Role of oxidative stress in the pathogenesis of acute pancreatitis. Scand J Gastroenterol Suppl 1996; 219: 10-15.

36. Serdar Z, Yesilbursa D, Dirican M, Sarandol E, Serdar A. Sialic acid and oxidizability of lipid and proteins and antioxidant status in patients with coronary artery disease. Cell Biochem Funct 2007; 25 (6): 655-664.

37. Chuang CC, Shiesh SC, Chi CH et al. Serum total antioxidant capacity reflects severity of illness in patients with severe sepsis. Crit Care 2006; 10 (1): R36.

38. Pascual C, Karzai W, Meier-Hellmann A et al. Total plasma antioxidant capacity is not always decreased in sepsis. Crit Care Med 1998; 26 (4): 705-709.

39. Tsai K, Hsu T, Kong C, Lin K, Lu F. Is the endogenous peroxyl-radical scavenging capacity of plasma protective in systemic inflammatory disorders in humans? Free Radic Biol Med 2000; 28 (6): 926-933.

40. Norman JG, Fink GW, Franz MG. Acute pancreatitis induces intrapancreatic tumor necrosis factor gene expression. Arch Surg 1995; 130 (9): 966-970.

41. Guice KS, Oldham KT, Remick DG, Kunkel SL, Ward PA. Antitumor necrosis factor antibody augments edema formation in caeruleininduced acute pancreatitis. J Surg Res 1991; 51 (6): 495-499.

42. Triantafillidis JK, Cheracakis P, Hereti IA, Argyros N, Karra E. Acute idiopathic pancreatitis complicating active Crohn's disease: favorable response to infliximab treatment. Am J Gastroenterol 2000; 95 (11): 3334-3336.

43. Fefferman DS, Alsahli M, Lodhavia PJ, Shah SA, Farrell RJ, Triantafillidis RE et al.Acute idiopathic pancreatitis complicating active Crohn's disease: favorable response to infliximab treatment. Am J Gastroenterol 2001; 96 (8): 2510-2511.

Received November 11, 2013. Accepted November 22, 2013. 